\section{Commentary: Surgical necessity is the mother of innovation when determining left ventricular assist device inflow access}

\author{
Tyler M. Bauer, MD, ${ }^{a}$ and Paul C. Tang, $\mathrm{MD}, \mathrm{PhD}^{\mathrm{b}}$
}

\begin{abstract}
Although the left ventricular (LV) apex is the most common site for LV assist device (LVAD) inflow cannulation, anatomic challenges (eg, calcification) at the apex will incite creativity for viable alternatives. Previous approaches have included diaphragmatic LVAD implantation as described by Gregoric and colleagues, ${ }^{1}$ as well as extensive debridement and patching of the LV apex as described by Atluri and colleagues. ${ }^{2}$ In this issue of JCTVS Techniques, Mangukia and colleagues ${ }^{3}$ present another novel approach by implanting a centrifugal LVAD in the anterolateral LV free wall.
\end{abstract}

Clearly, placement of the inflow cannula in a nonapical location would require an anatomic awareness of potential interactions with functional cardiac components. Considerations can be broadly described as (1) interference with the mitral apparatus, (2) obstruction of the LVAD inflow, and (3) quality of the left ventricle. We address each of these points in sequence.

First, maintaining the integrity of the mitral valve apparatus is an important consideration, given recent reports suggesting that residual moderate to severe mitral regurgitation post-LVAD can contribute to right heart failure, stroke, and hospital readmission and potentially impact survival. ${ }^{4,5}$ Furthermore, LVAD ingestion of mitral leaflet and anchoring components can predictably cause device complications as well as contribute to regurgitation by distorting

\footnotetext{
From the Departments of a Surgery and ${ }^{\mathrm{b}}$ Cardiac Surgery, University of Michigan, Ann Arbor, Mich.

Disclosures: The authors reported no conflicts of interest.

The Journal policy requires editors and reviewers to disclose conflicts of interest and to decline handling or reviewing manuscripts for which they may have a conflict of interest. The editors and reviewers of this article have no conflicts of interest.

Received for publication April 14, 2021; revisions received April 14, 2021; accepted for publication April 22, 2021; available ahead of print April 27, 2021.

Address for reprints: Paul C. Tang, MD, PhD, Department of Cardiac Surgery, University of Michigan, Ann Arbor, MI 48109 (E-mail: tangpaul@med.umich.edu). JTCVS Techniques 2021;8:93-4

2666-2507

Published by Elsevier Inc. on behalf of The American Association for Thoracic Surgery. This is an open access article under the CC BY-NC-ND license (http:// creativecommons.org/licenses/by-nc-nd/4.0/).

https://doi.org/10.1016/j.xjtc.2021.04.021
}

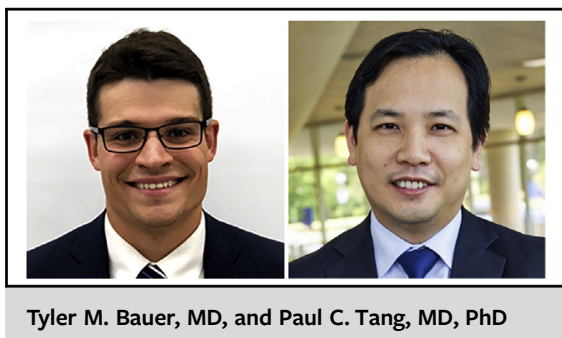

CENTRAL MESSAGE

Anterolateral LVAD implantation

with a hostile apex is a novel option. Careful consideration of mitral proximity, avoidance of inflow obstruction and assessing myocardial integrity are critical components.

valvular components. The authors outline a strategy for staying $3 \mathrm{~cm}$ away from the base of the papillary muscle to avoid this issue; however, this might not be possible depending on the LV cavity size.

Second, the risk of inflow obstruction in the anterolateral position will be determined by the size of the LV cavity, as well as the available location for LV cannulation. A large LV cavity would allow a greater margin of safety for avoiding suction events over a wider range of pump speeds and facilitate precise adjustments in cannula positioning. Careful placement of a retraction stitch on the ribs is an integral component in optimizing alignment with the atrioventricular junction.

Third, inflow cannula placement in an anterolateral location requires a retraction stitch to realign the LVAD with the mitral valve and avoid obstruction by the septum. This necessarily places undue stress on the LV wall, which seems to be tolerated in a large left ventricle with a pliable and thinned wall after LVAD support and decompression. A smaller LV cavity with a thicker wall likely is much less forgiving of the compression and retraction forces placed on it to achieve favorable alignment. Furthermore, the intrinsic quality of the LV wall, such as the presence of thrombus and friability (eg, recent myocardial infarction), are also important considerations in determining whether this approach is reasonable.

When dealing with a hostile LV apex during LVAD implantation, meticulous evaluation of unique anatomic challenges is needed to select an individualized approach. Mangukia and colleagues propose an 
innovative anterolateral access approach with its own unique set of candidacy considerations. Longer-term results would be welcomed when this technique is more broadly adopted for bridge-to-transplantation or destination indications. It would be important to determine its compatibility with myocardial recovery and device explantation.

\section{References}

1. Gregoric ID, Cohn WE, Frazier OH. Diaphragmatic implantation of the HeartWare ventricular assist device. J Heart Lung Transplant. 2011;30:467-70.
2. Atluri P, Dymond DJ, Woo YJ. Continuous-flow left ventricular assist device implantation in the presence of a hostile ventricular apex. J Thorac Cardiovasc Surg. 2013;146:981-2.

3. Mangukia C, Sunagawa G, Brann S, Hamad E, Toyoda Y. Modified technique for left ventricular assist device insertion in the setting of apical calcification. J Thorac Cardiovasc Surg Tech. 2021;8:90-2.

4. Tang PC, Haft JW, Romano MA, Bitar A, Hasan R, Palardy M, et al. Right ventricular function and residual mitral regurgitation after left ventricular assist device implantation determines the incidence of right heart failure. J Thorac Cardiovasc Surg. 2020;159:897-905.e4.

5. Robertson JO, Naftel DC, Myers SL, Tedford RJ, Joseph SM, Kirklin JK, et al. Concomitant mitral valve procedures in patients undergoing implantation of continuous-flow left ventricular assist devices: an INTERMACS database analysis. J Heart Lung Transplant. 2018;37:79-88. 